\title{
Subject Index Vol. 39, No. 1-2, 1996
}

\section{AIDS 72}

Antigen delivery system 93 Assembly 32 Baculovirus 40, 126

- $\quad$ vectors 62

Bluetongue virus 62

Carcinogenesis 54

CD8+cytotoxicTlymphocytes 111

Chimera 126

Chimeric proteins 9, 16

- $\quad$ viruses 72

Circumsporozoite antigen 104 Cloning 9, 16

Coat proteins 9 Combinatorial libraries 72 Core-like particles 62 Core particles 104 Cowpea mosaic virus 79

- $\quad$ plants 79

Cytotoxic T lymphocytes 120 Disulfide bonds 49 DNA-based immunization 120 DNA vaccine 120 Endocytic vesicles 49 Epitope presentation 104 Epitopes 126 Gag proteins 32 Genetic engineering 9, 16 HBeAg 104 Hepatitis B core antigen 16,104

- surface antigen 23

- virus 23, 104, 120, 126

- - small surface antigen 111

- - surface protein, large 23 Human immunodeficiency virus 32, 40

- - typel 79,93

Immunodominant epitopes 16 Immunoelectron microscopy 40 Immunogenicity 93 Internet,

DNA vaccines 120 Luteinizmg hormone releasing hormone 85 Malaria 85, 104

- $\quad$ vaccine 104

MHC class I restricted antigen presentation

111 Mutagenesis, in vitro 32 Neoplasia 54 Papillomavirus 49, 54

- $\quad$ vaccine 49

Particle purification 85

Particulate vaccines 40

Peptides, synthetic 32

Potyvirus-like particles 85

Pseudovirion 40

Rhinoviruses, human 72, 79

RNAphageQß 9

Schistosomiasis 85

Self-assembly 85

Surface antigen 120 T-helper phenotype 120 Twelve steps, DNA-mediated immunization 120 Vaccines 54, 62, 72, 85 Vector 120

Virion morphogenesis 23 Virus assembly 126 
- $\quad$ crystals 79

Virus-like particles 40, 49, 54, 62, 93, 126

-, vaccines 111

X-ray diffraction 79 